\title{
Investigation of Mechanical And Tribological Properties of Boric Acid Reinforced Composite Plates
}

\author{
Taner Aydın' ${ }^{1}$, Kadir Turan ${ }^{2} \mathbb{D}$, Nejat Yıldırım Sarı ${ }^{3}$ (D) \\ ${ }^{1}$ Dicle University, Mechanical Engineering Department, Diyarbakır, Turkey.(e-mail: taner.aydin@ dicle.edu.tr). \\ ${ }^{2}$ Dicle University, Mechanical Engineering Department, Diyarbakır, Turkey.(e-mail: kturan@ dicle.edu.tr). \\ ${ }^{3}$ Kocaeli University, Mechanical Engineering Department, Kocaeli, Turkey. (e-mail: nsari@kocaeli.edu.tr).
}

\section{ARTICLE INFO}

Received: Apr., 21. 2021

Revised: Feb., 05. 2021

Accepted: Dec., 27. 2021

\section{Keywords:}

Composite materials

Boric acid

Wear resistance

Tensile test

Hybrid composite material

Corresponding author: Kadir Turan

ISSN:2536-5010| e-ISSN: 2536-5134

\section{ABSTRACT}

In this study, the mechanical and tribological properties of unidirectional glass fiber/polyester resin and unidirectional carbon fiber / polyester resin composite materials reinforced with boron particles have been investigated by experimental methods. Composite plates were produced by hand lay-up method using polyester resin mixed with boric acid particles $\left(\mathrm{H}_{3} \mathrm{BO}_{3}\right)$ with a specific gravity of $1.51 \mathrm{~g} / \mathrm{cm} 3$ and a molecular weight of 61.83 $\mathrm{g} / \mathrm{mol}$, which were utilized as boron particles. As particle reinforcement, $1 \%, 5 \%$ and $10 \%$ boron oxide polyester resin mixture was obtained. The effects of particle reinforcement on mechanical and tribological properties were investigated. As a result of the experimental studies, it was determined that, due to the increase in the particle ratio, the wear resistance increased by between the ratios $5 \%$ and $50 \%$ in some samples compared to the samples not reinforced with boric acid particles and the tensile strength improved up to $32 \%$ in some samples.

DOI: https://doi.org/10.36222/ejt.923954

\section{INTRODUCTION}

Due to the decreasing resources and increasing needs, the discovery and development of new materials in harmony with the developing technology have emerged in order to meet those needs. As responses to the aforementioned needs, composite materials have emerged as materials with new properties, those that are different from the materials combined to form them. One of the most important features of composites is that they can respond to unlimited demands with unlimited production options. They are produced by wrapping strong, stiff fibers in relatively weaker and less solid matrix materials [1]. The materials which have gained more and more usage in industrial market, that have high technical performance and knowhow requirement an in addition to those have high added value can be called high-tech materials.[2]

Composite materials are widely used in areas such as automotive, aerospace, textile industry, sports equipment, food and construction industry. Usage areas of composite materials continues to grow day by day in the world and in our country. The composite material industry has come to a very important point thanks to various innovations and advanced technology applied on the materials that make them chemically, physically and mechanically different, forming the composite material, matrix materials and reinforcing fibers. Polymer matrix composite materials are the most widely used composite materials. Fibers such as carbon, aramid and glass are especially used to increase the strength values of polymer matrix composite materials. In addition to the fibers used, it is also possible to use various particles by adding them to polymer matrix composite materials because their properties such as wear resistance, rigidity and bending strength are not good enough. The addition of the mentioned particles highly affects the physical and mechanical properties of the composite material [3-4]. There are many studies on particle reinforced composite materials in the literature. Navaneethakrishnana et al. [5] prepared boron nitride $(\mathrm{BN}) /$ epoxy nano composites containing different percentages of $\mathrm{BN}$ particles by liquid casting process. They analyzed the mechanical properties of composites such as hardness, tensile, bending and impact strength. Venkatesh Vijayaraghavan et al. [6] presented a comprehensive study with the help of molecular dynamic analysis of tensile loading mechanics of polyethylene (PE) nano composites reinforced with $\mathrm{BN}-\mathrm{C}$ nano layers. They observed that the geometry and lattice arrangement of BN - C nano layers affect the tensile load properties of nano 
composites. MeysamRahmat et al. [7] examined the quasistatic and dynamic performances of epoxy in two different classes which are with and without Boron nitride nanotubes (BNNTs). In addition to pure epoxy material, they also tested samples with concentrations of $1 \%$ and $2 \%$ BNNT by weight. In addition, they noted that the BNNT-modified tensile specimens showed up to $7 \%$ increase in tensile strength, up to $16 \%$ increase in modulus, and a $9 \%$ decrease in strain rate. Xiao Zhang1 et al. [8] produced a BN / PVDF composite by hot press method in their study. They stated that the distribution of BN is homogeneous, dense and directed towards PVDF (Polyvinylidenefluoride). They also stated that the thermal conductivity and tensile performance of the composite were greatly improved. Also, the thermal conductivity was measured as $0.57 \mathrm{~W} /(\mathrm{mK})$, which is an increase of $307 \%$ compared to pure PVDF. Burroughs et al. [9] investigated the utility of boric acid particles in PTFE and epoxycomposite materials that are in slip contact with stainless steel. They stated that when boric acid is used as a filler, it reaches the level of 10-5 mm3 / N-m by providing a twenty-year decrease in the rate of wear. They reported that with sufficient ambient moisture, a reduced wear rate can be achieved without causing counter-surface wear and the friction of PTFE will be further reduced. They stated that boric oxide fillers in such environments can reduce the friction coefficient of epoxy from $\mu>0.7$ to $\mu=0.07$. Cavdar et al. [10] investigated the effect of boron-based flame retardants (BbFRs) and fiber loading on the mechanical, fire and thermal performances of impregnated spruce wood (WF), which is a filled high density polyethylene composite. For this purpose, they impregnated WF with boric acid solution, borax and their mixtures and dried before composite production. The effect of the separation on the limiting oxygen index (LOI) levels of the BbFR samples were also investigated. According to the test results, samples with borax provided better mechanical properties compared to samples containing boric acid and showed a $19 \%$ improvement in tensile modulus in those with $40 \%$ fiber loading compared to control samples. Hou et al. [11] investigated the effects of modified $\mathrm{BN}$ content on thermal and insulating properties by using hexagonal boron nitride micro particles modified with 3-aminopropyl triethoxysilane (APTES) to fabricate thermally conductive epoxy / BN composites. They found that the using h-BN particles as reinforcement to the epoxy matrix significantly increased the thermal conductivity of composites. They found the thermal conductivity of composites with a modified BN loading of $30 \%$ by weight is 6.14 times higher than that of pure epoxy, at 1.178 W m-1 K-1. Myshkin et al. [12] stated in their study that the tribological behavior of polymers was reviewed from the middle of the 20th century to the present. They said that with the new contact tack gauge, the surface energy of different coatings can be determined. They discussed friction with adhesion and deformation components. They demonstrated how load, sliding speed and temperature affect friction. Li et. al. [13] have stated as their article's main purpose, using solid lubricants such as polytetrafluroethylene (PTFE), ultra-high molecular weight polyethylene (UHMWPE) and a combination of the two, is to further optimize the tribological properties of glass fiber reinforced PA6 (GF / PA6,15 / 85 by weight) for high performance friction materials. They investigated the synergies of the tribological properties of these materials resulting from the inclusion of PTFE and UHMWPE. They stated that the results showed that at a load of $40 \mathrm{~N}$ and a speed of $200 \mathrm{rpm}$, PTFE was effective in improving the tribological abilities of the matrix material. They found that the combination of PTFE and UHMWPE further reduced the friction coefficient of composites mixed with only PTFE or UHMWPE. They also discussed the effects of load and speed on tribological behavior. In order to better understand the mechanism of wear, they examined the eroded surfaces with a scanning electron microscope. Karatas et al. [14] stated that polyamide 6,6 (PA6,6) is one of the widely used engineering polymers and is being used for various applications. Moreover, they stated that the tribological and mechanical performance of PA6,6 could be improved by adding fibers or particles. However, they stated that the properties of reinforced PA6,6 matrix composites would be affected by many factors. They explained that the interfacial adhesion between the reinforcement and the matrix material is one of these factors and that good interfacial adhesion is required to obtain good final properties. They aimed to improve the tribological and mechanical properties of carbon fiber reinforced PA6,6 composites by improving fiber-matrix interaction by using graphennanoplatelet (GNP) and 1,4-phenylene-bis-oxazoline (PBO). They performed adhesive wear test, tensile test, dynamic mechanics, differential scanning calorimetry and scanning electron microscopy analyses. As a result, all test results showed that composites coded CF_0.5GNP_PBO exhibit improved tribological and mechanical properties among all composites.

In this study, it is aimed to determine the wear behavior and mechanical properties of composite plates reinforced with boron particles. For this purpose, boric acid particles with a specific gravity of $1.51 \mathrm{~g} / \mathrm{cm} 3\left(20^{\circ} \mathrm{C}\right)$ and a molecular weight: $61.83 \mathrm{~g} / \mathrm{mol}$ were mixed with polyester resin in the ratio of $1 \%, 5 \%$ and $10 \%$ by weight. Glass fiber / polyester and carbon fiber / polyester composite plates were produced by absorbing the obtained boric acid-added polyester resin on unidirectional glass fiber and unidirectional carbon fibers by hand lay-up and cold press method. Glass fiber / polyester and carbon fiber / polyester composite plates were produced with neutral resin as the control group. Wear tests and tensile tests of the composite plates obtained were applied. The obtained results are presented in tables and graphics.

\section{EXPERIMENTAL STUDY}

In this study, unidirectional glass fiber with a density of 250 $\mathrm{g} / \mathrm{m} 2$, turquoise brand polyester resin which is a nonthixotropic, non-accelerated, low reactive, low viscosity, orthophthalic based unsaturated suitable for hand lay-up and spray applications. It has the ability to quickly wet the fiber, coded as TP 220 and boric acid particles $\left(\mathrm{H}_{3} \mathrm{BO}_{3}\right)$ with a specific weight of $1.51 \mathrm{~g} / \mathrm{cm} 3\left(20^{\circ} \mathrm{C}\right)$ and a molecular weight: $61.83 \mathrm{~g} / \mathrm{mol}$ which were supplied from Etimaden plants have been used. Composite materials containing unidirectional glass fiber and carbon fiber are prepared by reinforcing with $1 \%, 5 \%$ and $10 \%$ boric acid by weight and also without reinforcement as pure. $1 \%, 5 \%$ and $10 \%$ by weight of boric acid was mixed into the polyester resin and mixed with the help of a mixer. The obtained boric acid reinforced polyester resin was impregnated on each fiber layer by hand lay-up method and at the end, it was left to cure for 12 hours under $5 \mathrm{MPa}$ pressure in cold press. Figure 1 shows the production method. 


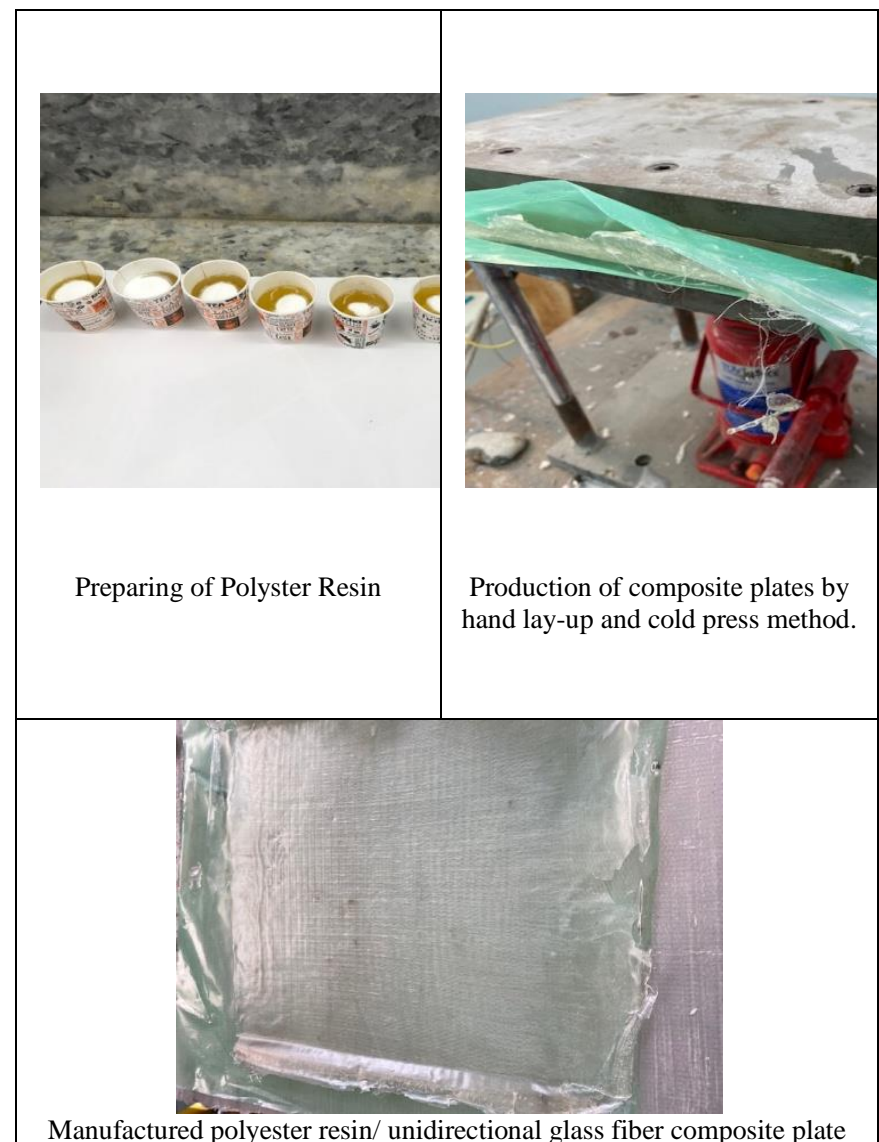
Figure 1 Production Method

Boric acid composition ratios and codes of the samples produced within the scope of the study are given in Table 1.

TABLE I

BORIC ACID COMPOSITION RATIOS AND CODES OF SAMPLES

\begin{tabular}{|c|c|c|}
\hline $\begin{array}{l}\text { Sample } \\
\text { Name }\end{array}$ & $\begin{array}{c}\text { Boric Acid } \\
\text { Reinforcement } \\
\text { Percentage } \\
\end{array}$ & Symbolic Notation \\
\hline \multirow{4}{*}{$\begin{array}{c}\text { Unidire } \\
\text { ctional } \\
\text { Glass } \\
\text { Fiber }\end{array}$} & Pure & N-0-TYCF \\
\hline & $1 \%$ & 1-0-TYCF \\
\hline & $5 \%$ & 5-0-TYCF \\
\hline & $10 \%$ & 10-0-TYCF \\
\hline \multirow{4}{*}{$\begin{array}{c}\text { Unidire } \\
\text { ctional } \\
\text { Carbon } \\
\text { Fiber }\end{array}$} & Pure & N-90-TYCF \\
\hline & $1 \%$ & 1-90-TYCF \\
\hline & $5 \%$ & 5-90-TYCF \\
\hline & $10 \%$ & 10-90-TYKF \\
\hline
\end{tabular}

\subsection{Wear Test}

Wear test was applied in order to determine the tribological properties of unidirectional glass fiber and carbon fiber reinforced composite materials containing neutral, $1 \%, 5 \%$ and $10 \%$ boric acid by weight, by cutting the plates obtained in 300 $\mathrm{mm} \times 215 \mathrm{~mm}$ dimensions and $1.2 \mathrm{~mm}$ thickness in $30 \times 30 \mathrm{~mm}$ dimensions. The relevant test was carried out using a
"Nanovea" brand "pin-on-disc" type tribometer device in Kocaeli University, Mechanical Engineering Department, Construction Laboratory. The wear test device is shown in Figure 2.

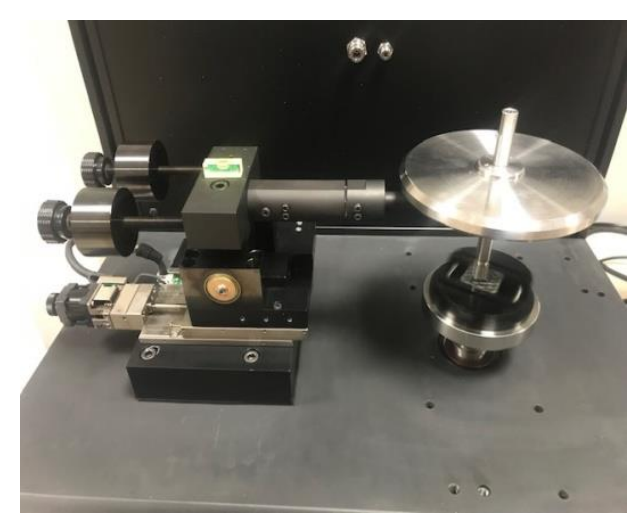

Figure 2. Nanovea Brand Wear Test Device

During the test, a $3 \mathrm{~mm}$ radius AISI 52100 steel metal ball was fixed to the load arm. The sample was placed on a rotating disk with a friction radius of $5 \mathrm{~mm}$. All wear tests were carried out with 150 RPM rotation speed, $20 \mathrm{~N}$ contact load and sliding distance set to $50 \mathrm{~m}$. During the test, the deformation on the samples was observed and recorded. The results of the wear test were automatically recorded by the computer, and the graphics and tables below were created based on these data.

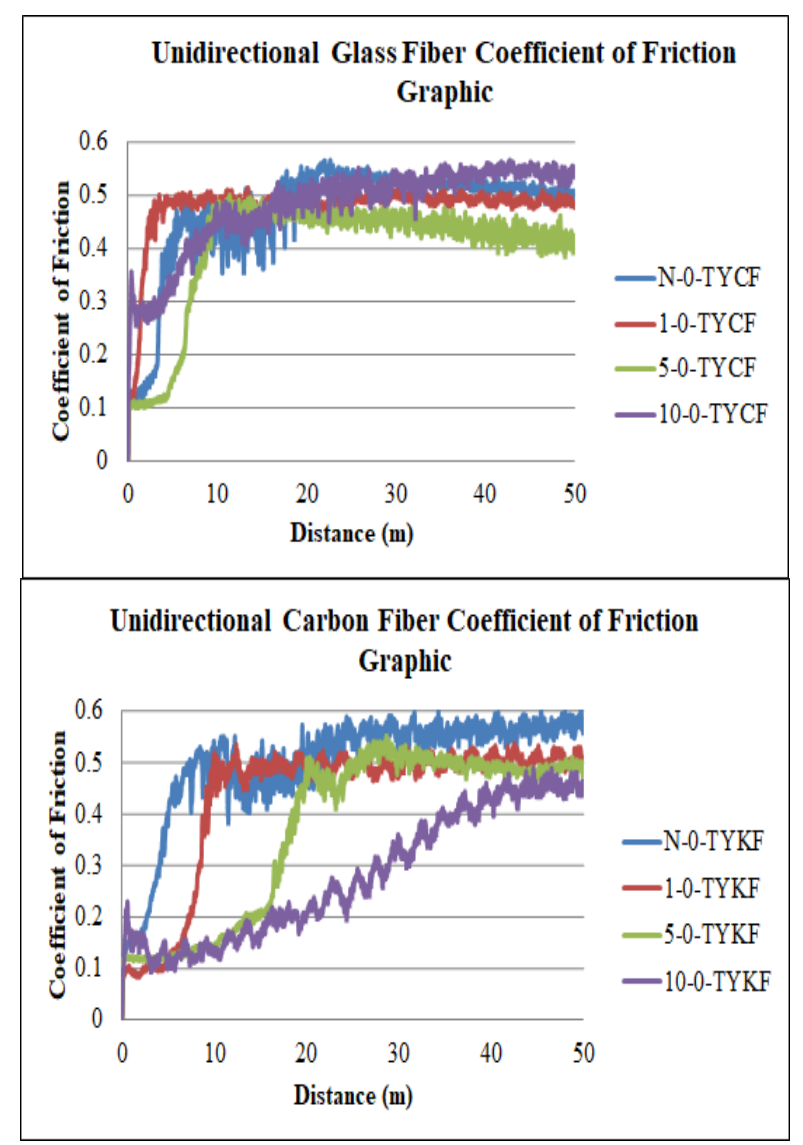

Figure 3. Coefficient of Friction Graphics Obtained As a Result of The Wear Test

The effect of boric acid reinforcement on the friction coefficient according to the sliding distance is shown in Figure 3. Due to the weak Van der Waals bonds of the solid lubricants, 
the bonds between the two-dimensional layers cause easy sliding properties between the layers during the wear test period. In this case, it causes the lubrication effect of boric acid to appear and thus to reduce the friction coefficient.

\subsection{Static Tensile Test}

Static tensile tests were carried out at the Dicle University Mechanics laboratory and Dicle University Central laboratories. Tests were carried out in 3 samples from each prepared sample. During the tests, an Instron BS 8801 servo hydraulic tensile test device with a capacity of $100 \mathrm{kN}$ was used. Tests were carried out in accordance with ASTM standards at room temperature. (ASTM - D, 1982). Tests have been carried out with the assumption that ambient humidity has no effect. The device is set so that the drawing speed is $1 \mathrm{~mm} / \mathrm{min}$. The lower jaw of the test device is movable and the upper jaw is fixed. When the samples are being positioned in the device, attention has been paid to ensure that there is no angular displacement between the lower jaw and the upper jaw so that equal distribution of the force applied to both sides is ensured. During the test, the ways in which the samples were damaged were observed and the necessary information notes were taken. The damage loads and displacements obtained after the relevant test was applied were automatically recorded on the computer and graphics and tables were created using this data. Figure 4 shows the test setup.

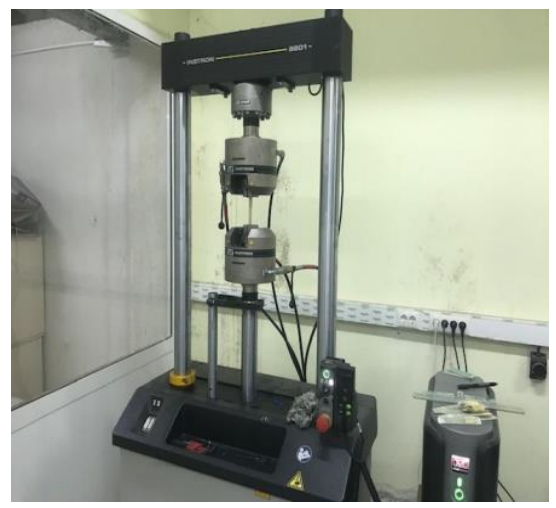

Figure 4. Instron Brand Tensile Test Device

In the static tensile tests applied to the produced composite plates, $\left[0^{\circ}\right]_{4}$ unidirectional glass fiber and $\left[0^{\circ}\right]_{4}$ carbon fiber plates were used. While the plates were being produced; into the polyester resin, $1 \%, 5 \%$ and $10 \%$ by weight of boric acid was added and non-reinforced polyester resin was used. In static tensile tests, three samples were produced for each parameter and the experiments were repeated. The obtained load-displacement ratios are presented in Figure 5.

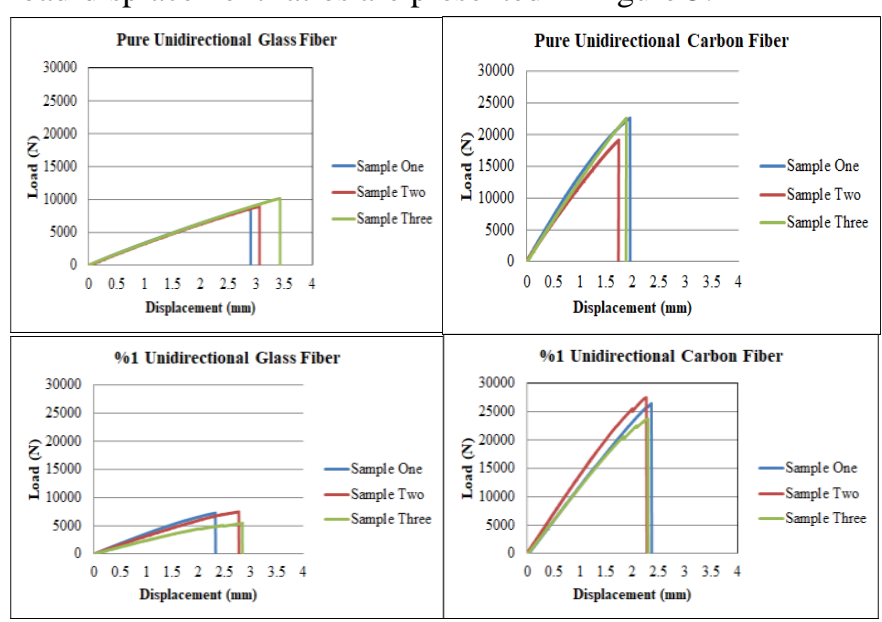

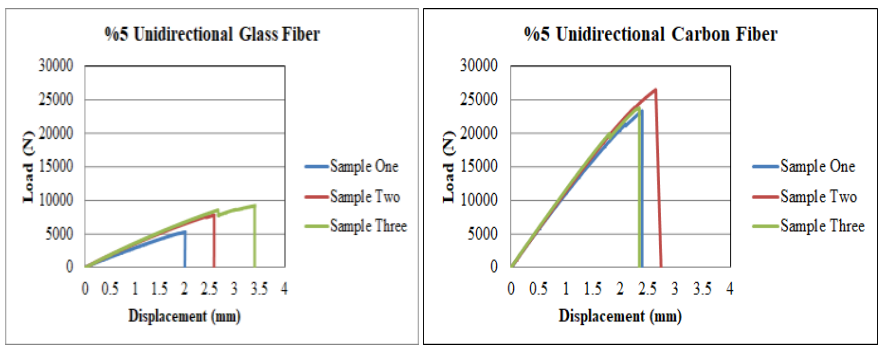

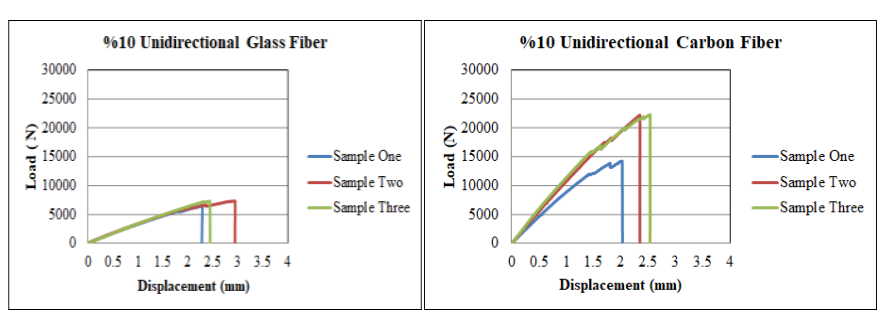

Figure 5. Graphics of Load (N) And Displacement (mm) Obtained As a Result of Tensile Test

In Figure 5, the load/displacement results of unidirectional glass and carbon fiber reinforced composite materials prepared by neutral and adding $1 \%, 5 \%$ and $10 \%$ boric acid by weight are shown graphically.

As can be seen from the figure, the load/displacement graphs of unidirectional glass fiber and unidirectional carbon fiber hybrid composite materials increase linearly. It is seen that damage occurs by instant breakage. The numbers of the samples are shown as 1,2 and 3 in the graphics.

\section{RESULTS AND DISCUSSION}

In this study, the tribological and mechanical properties of the composite materials was experimentally investigated as the effect of the addition of boric acid in various additive ratios to the matrix material. The results were evaluated by applying the wear test and tensile test to the samples prepared by adding $1 \%$, $5 \%$ and $10 \%$ boric acid by weight.

\subsection{Effects of using boric acid as reinforcement for wear resistance}

As a result of the wear tests, the average friction coefficient values obtained as a result of the wear test of polyester/unidirectional glass fiber and polyester/unidirectional carbon fiber composite plates, which were not reinforced and reinforced with $1 \%, 5 \%$ and $10 \%$ by weight of boric acid, are presented in Figure 6.

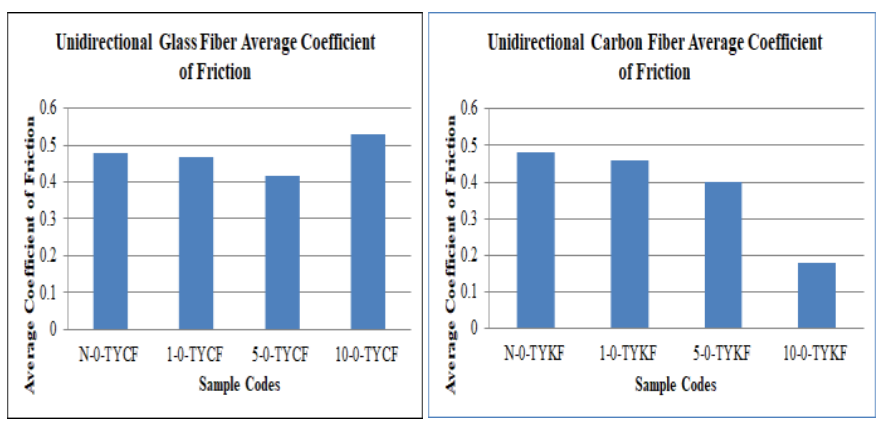

Figure 6. Wear Average Coefficient Variation Graph of Boric Acid Reinforced $\left[0^{\circ}\right]_{4}$ Polyester/Unidirectional Glass Fiber And $\left[0^{\circ}\right]_{4}$ Polyester/Unidirectional Carbon Fiber Composites.

It is seen from the literature that boric acid is used as a solid lubricant. Tribological contacts (friction and wear) typically 
result in the transfer of a thin layer of material from the surface of the solid lubricant coating to the opposite surface, commonly known as a transfer film or tribofilm. A good transfer film formed by matrix material and solid lubricant increases the wear resistance by decreasing the friction coefficient. Boric acid also has a lubricating effect due to its good sliding property between its layers. Thanks to this effect, the friction coefficient of the polymer composite material decreases during the wear process. [9-16] Under the light of these evaluations, it can be seen in Figure 3 that as the boric acid ratio increases, the wear resistance of the unidirectional glass fiber composite material increases.

The reason why the friction coefficient of $10 \%$ boric acid added polymer composite material is higher than other composite materials with unidirectional glass fiber samples may be that boric acid has agglomeration in this composite sample. [17-19]

\subsection{Effects of using boric acid as reinforcement for tensile strength}

The average tensile strength values obtained as a result of static tensile tests and the wear test of polyester/unidirectional glass fiber and polyester/unidirectional carbon fiber composite plates, which are not reinforced and reinforced with 1\%, 5\% and $10 \%$ boric acid by weight, are presented in Figure 7.

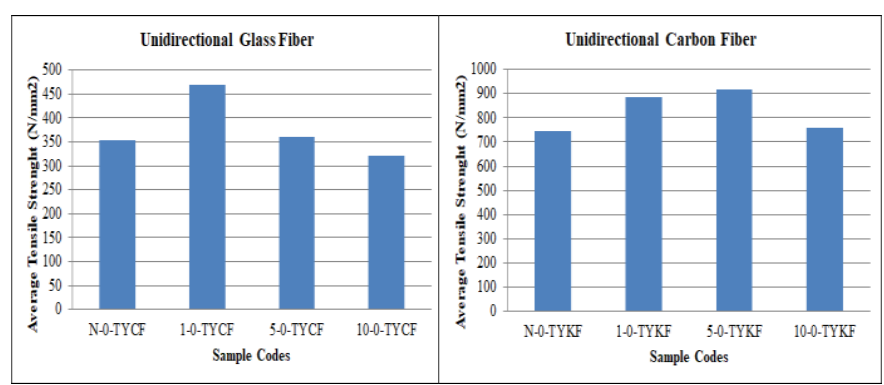

Figure 7. Average Tensile Strength Values of Unidirectional Glass Fiber and Unidirectional Carbon Fiber Composite Materials

When Figure 7 is examined, the average tensile strength value of unidirectional glass fiber hybrid composite materials, especially of the samples with $1 \%$ boric acid by weight, has increased. Again, in unidirectional carbon fiber hybrid composite materials, the average tensile strength values of the samples with $1 \%$ and $5 \%$ additives were increased. It is seen that the highest average tensile strength value in unidirectional glass fiber specimens is in the sample with $1 \%$ reinforced value with $469 \mathrm{~N} / \mathrm{mm} 2$, and the highest average tensile strength value in unidirectional carbon fiber specimens is in the sample that is $5 \%$ reinforced with a value of $915 \mathrm{~N} / \mathrm{mm} 2$. The results obtained have been shown in Table 2 in order to allow better understanding of the experimental study results.

When Table 2 is examined, it is seen that $1 \%$ by weight boric acid reinforcement can increase the average tensile strength by approximately $32 \%$ for unidirectional glass fiber composite samples. For unidirectional carbon fiber composite samples, it was observed that $5 \%$ by weight boric acid reinforcement can increase the average tensile strength by about $23 \%$. For unidirectional glass fiber composite samples $\% 10$ by weight boric acid reinforcement decrease the average tensile strength by approximately $9,03 \%$.And for unidirectional carbon fiber composite samples, $\% 10$ by weight boric acid reinforcement has little effect as \%1.97. After a certain amount of boron component reinforcement, it has been also shown in the literature that this components has a negative effect on average tensile strength or does not affect it at all. Boztoprak and Kartal [20] showed in their study that the tensile strength value decreased due to the increase in the boron nitride ratio. Navaneethakrishnan et al. [5] showed in their study that \% 1 by weight boron nitride reinforcement increased tensile strenght value on the other hand $\% 2$ by weight boron nitride reinforcement decreased. Taşgin, [21] reported that $\% 10$ by weight boric acid reinforcement decrease the average tensile strength compared to $\% 5$ by weight boric acid reinforcement.

TABLE II

Average Tensile Strength CHANGe RATE BASEd ON BorIC ACID ADDITIVE RATIO

\begin{tabular}{|c|c|c|c|c|}
\hline $\begin{array}{l}\text { Sample } \\
\text { Name }\end{array}$ & $\begin{array}{c}\text { Boric acid } \\
\text { Reinforcemen } \\
\text { t Percentage }\end{array}$ & $\begin{array}{l}\text { Symbolic } \\
\text { Notation }\end{array}$ & $\begin{array}{l}\text { Average } \\
\text { Tensile } \\
\text { Strengt } \\
\text { h Value( } \\
\text { N/mm2 ) }\end{array}$ & $\begin{array}{c}\text { Rate of } \\
\text { Chang } \\
\text { e }(\%)\end{array}$ \\
\hline \multirow{4}{*}{$\begin{array}{l}\text { Unidirectional } \\
\text { Glass Fiber }\end{array}$} & Neutral & N-0-TYCF & 354 & \\
\hline & $1 \%$ & 1-0-TYCF & 469 & (+) 32,4 \\
\hline & $5 \%$ & 5-0-TYCF & 360 & (+) 1,69 \\
\hline & $10 \%$ & 10-0-TYCF & 322,33 & (-) 9,03 \\
\hline \multirow{4}{*}{$\begin{array}{l}\text { Unidirectional } \\
\text { Carbon Fiber }\end{array}$} & Neutral & N-90-TYCF & 743 & \\
\hline & $1 \%$ & 1-90-TYCF & 884,66 & $\begin{array}{l}(+) \\
19,06\end{array}$ \\
\hline & $5 \%$ & 5-90-TYCF & 915,66 & $\begin{array}{l}+) \\
23,24\end{array}$ \\
\hline & $10 \%$ & 10-90-TYKF & 757,66 & (+) 1,97 \\
\hline
\end{tabular}

$*(+$ indicates that the rate of change is positive, - is negative)

\section{CONCLUSIONS}

The main purpose of this study is to investigate the effect of boric acid reinforcement on the mechanical and tribological properties of glass fiber/polyester and carbon fiber/polyester composite materials. Adhesion wear is defined as the wear of surfaces that are in contact with each other under the influence of normal force. Due to the fact that the surface areas of the surfaces in contact are very small, even if the force is constant, the applied pressure value is quite high. The surfaces in this situation are subject to plastic deformation. As a result of the relative movements of the contact surfaces, gaps are formed on the surface of the object, which is produced from soft material, due to the rupture of the aforementioned bonds, and particles begin to fall off between the two surfaces. During polymer transfer, it is seen that the wear volume and friction coefficient increase and the wear resistance decreases in parallel with the increase in the transfer amount.

It is evaluated that various additives that can be made to the matrix material in composite materials can reduce the surface to surface transfer amount and thus increase the wear resistance [20-23] In the study, it was determined that due to the lubricating effect of boric acid, its wear resistance increased with the addition of the matrix material. In addition, by adding boric acid to the matrix material to obtain hybrid composite material, the average tensile strength values have increased significantly depending on certain ratios by weight. The data obtained from this study will make a significant contribution to the determination of the mechanical and tribological properties of different fiber reinforcement angles and bi-directional fiber reinforced composite materials. The evaluations of the general results are presented below. 
- The addition of boric acid increases the average tensile strength up to a certain rate,

- Addition of boric acid in increasing rates brings improvements in the tribological properties of the composite material, and the wear resistance increases,

- If boric acid is used as reinforcement at more than a certain amount, results have been obtained suggesting that it does not change or reduce the average tensile strength value.

\section{REFERENCES}

[1] P. Mallick, 'Fiber reinforced composites', Department of Mechanical Engineering University of Michigan Deaborn, Michigan, 1993.

[2] E. Karaçay, E. Alp, H.C. Cabbar, 'Boron carbide production by solgel method and its characterization', Journal of the Faculty of Engineering and Architecture of Gazi University, 27(2), pp. 417-428, 2012

[3] S. K. Mazumdar, 'Composites manufacturing materials, product, and process engineering', CRC Press, London,, 2002, pp.20-39

[4] A.B. Strong, 'Fundamentals of composites manufacturing: materials, methods, and applications", $2^{\text {nd }}$ ed , SME, Michigan , 2008, pp.1-18.

[5] G. Navaneethakrishnan, T. Karthikeyan, S. Saravanan, V. Selvam, ' Influence of boronnitride on morphological, mechanical, thermal and wear characteristics of epoxy nano composites", Mater. Res. Innov., 24:5, pp. 257-262, 2020.

[6] V. Vijayaraghavan, L. Zhang, 'Tensile and interfacial loading characteristics of boron nitride-carbon nanosheet reinforced polymer nanocomposites"'. Polymers. 11(6), pp. 1075, 2019.

[7] M. Rahmat, A. Naftel, B. Ashrafi, M.B. Jakubinek, Y. Martinez-Rubi, B. Simard, 'Dynamic mechanical characterization of boron nitride nanotube-epoxy nano composites', Polym. Compos., 40 , pp. 21192131, 2019

[8] X. Zhangand J. Zheng, 'Polymer composites with enhanced mechanical and thermal properties by orientating boron nitride flakes", IOP Conf. Ser.: Mater. Sci. Eng. 493, 012137, 2019.

[9] B. R Burroughs, J. H. Kim, T. A. Blanchet, B' oric acid self-lubrication of B2O3-filled polymer composites', Tribol. Tran., 42(3), pp.592-600, 1999.

[10] A. D. Cavdar, F. Mengeloğlu, K. Karakus. 'Effect of boric acid and borax on mechanical, fire and thermal properties of wood flour filled high density polyethylene composites", Measurement, 60, pp. 6-12, 2015.

[11] J. Hou, G. Li, N.Yang, L Qin, M. E. Grami, Q Zhang., N. Wang, X. Qu, 'Preparation and characterization of surface modified boron nitride epoxy composites with enhanced thermal conductivity", Chem.Sci., 4, pp. 44282-44290, 2014

[12] N. K. Myshkin, M. I. Petrokovets, A. V. Kovalev, (2005). Tribology of polymers: adhesion, friction, wear and mass-transfer, Tribol. Int., 38, pp. 910-921, 2005

[13] D. X. Li, Y. L. You, X. Deng, W. J. Li, Y. Xie, ' 'Tribological properties of solid lubricants filled glass fiber reinforced polyamide 6 composites', Mater. Des., 46, pp. 809-815, 2013.

[14] E. Karatas, O. Gul, N. G. Karsli, T. Y1lmaz, "Synergetic effect of graphene nanoplatelet, carbon fiber and coupling agent addition on the tribological, mechanical and thermal properties of polyamide 6,6 composites", Com. B. Eng., 163, pp. 730-739, 2019.

[15] T. W. Scharf, S. V. Prasad, 'Solid lubricants: a review', J. Mater. Sci.,48, pp. 511-531, 2013.

[16] M. Demir, Y. Çelik, , E. Kılıçkap, 'Cam ve karbon elyaf takviyeli kompozitlerde elyaf cinsinin, yükün, kayma hızı ve mesafesinin abrazif aşınmaya etkisi',, Politeknik Dergisi, 22, pp. 811-817, 2019.

[17] D. Pedrazzoli, A. Pegoretti, K. Kalaitzidou, 'Synergistic effect of exfoliated graphitenano plateletsand short glass fiber on the mechanical and interfacial properties of epoxy composites", Compos. Sci. Technol., 98, pp. 15-21, 2014.

[18] S.Y. Yang, W.N. Lin, Y.L. Huang, H.W. Tien, J.Y. Wang, C.C.M. Ma, S.M. Li, Y.S. Wang, "Synergetic effects of graphene plateletsand carbon nano tubes on the mechanical and thermal properties of epoxycomposites"', Carbon, 49, pp. 793-803, 2011.

[19] X. Yang, Z. Wang, M. Xu, R. Zhao, X. Liu, ''Dramatic mechanical and thermal increments of thermo plastic composites by multi-scale synergetic reinforcement: carbon fiber and graphene nano platelet', Mater. Des., 44, pp. 74-80, 2013.
[20] Y. Boztoprak, İ. Kartal, '’Bor nitrür partikülleriyle takviyelendirilmiş vinil ester matrisli kompozitlerin mekanik özelliklerinin incelenmesi', ECJSE, 6(1), pp. 45-50, 2019.

[21] Y Taşgın, 'Katalizör olarak katılan bor oksit ve borik asidin polyester üzerindeki etkilerinin mekanik ve mikro yapı açısından incelenmesi', Frrat Üniversitesi Mühendislik Bilimleri Dergisi, 30, pp. 303-311, 2018.

[22] W. Brostow, V. Kovačević, D. Vrsaljko, J. Whitworth, 'Tribology of polymers and polymer-based composites', J. Mater. Educ., 32, (5-6), pp. 273-290, 2010.

[23] H. Dong, T. Bell, 'State-of-the-art overview: Ion beam surface modification of polymers towards improving tribological properties", Surf. Coat. TechnoL., 111, pp. 29-40, 1999.

[24] S. K. Sinha, B. J. Briscoe, 'PolymerTribology', $1^{\text {st }}$ ed., Imperial College Press, London, 2009.

[25] N. G. Karsli, S. Demirkol, T. Yilmaz, 'Thermal aging and reinforcement type effects on the tribological, thermal, thermomechanical, physical and morphological properties of poly(etheretherketone) composites', Com. B. Eng., 88, pp. 253-263, 2016 .

\section{BIOGRAPHIES}

Taner Aydin received his bachelor's degree in mechanical engineering from Kocaeli University, Turkey in 2012. He began studying for a master's degree at Kocaeli University in 2018. He has been working as a reserch assistant at Dicle University since 2020. He works on boron reinforced composite materilas.

Kadir Turan received the B.S. degree from the Mechanical Engineering Department, Firat University, Elazığ, Turkey, in 2000, and the M.S. degrees from the Frrat University in 2003 and $\mathrm{PhD}$ degrees from the Frrat University in 2009 He appointed as an Assistant Professor in 2011, Associate Professor in 2014, and Professor 2020 to the same department. His research interests include mechanics of composite materials, finite element method, wreckage analysis.He has 12 articles in SCI-indexed journals and 15 articles in national journals.

Nejat Yıldırım Sarı received the B.S. degree from the Mechanical Engineering Department, Yildiz Technical University (YTU), Istanbul, Turkey, in 1987, and the M.S. degrees from the Yildiz Technical University in 1992 and $\mathrm{PhD}$ degrees from the Istanbul Technical University in 1999. He is currently an associate professor at the Kocaeli University. His research interests Mechanical Engineering,Tribology,Engineering and Technology. 